\title{
Produção de melão Cantaloupe influenciado por coberturas do solo, agrotêxtil e lâminas de irrigação
}

\author{
José Francismar de Medeiros ${ }^{1}$;Saint Clair L Santos ${ }^{1}$; Maria José T Câmara ${ }^{1}$; Maria Zuleide de Negreiros ${ }^{1}$ \\ ${ }^{1}$ UFERSA, NPG, C. postal 137, 59625-900 Mossoró-RN; jfmedeir@ufersa.edu.br
}

\begin{abstract}
RESUMO
Dois experimentos foram conduzidos simultaneamente em uma mesma área, no município de Baraúna (RN), de outubro a dezembro de 2003, com o objetivo de estudar o uso de cobertura do solo com filmes plásticos e lâminas de irrigação, bem como o uso de agrotêxtil, na produção de melão Cantaloupe. Em um experimento foi utilizado o agrotêxtil, enquanto no outro não. Em cada experimento estudou-se o efeito de cinco coberturas (solo descoberto, cobertura com plástico preto, prateado, amarelo e marrom) e três lâminas de irrigação $(100 \%, 84 \%$ e $67 \%$ da lâmina padrão de $270 \mathrm{~mm}, \mathrm{~L} 1)$, em esquema fatorial $5 \times 3$, no delineamento de blocos casualizados completos com duas repetições. Foram avaliados o número, massa média e produtividade de frutos comercializáveis (mercados interno e externo), refugos e totais. $\mathrm{O}$ uso do agrotêxtil aumentou o número de frutos e produtividade. Na ausência do agrotêxtil, a cobertura do solo com plástico amarelo aumentou a produtividade comercial em relação ao solo descoberto, enquanto que, na presença do agrotêxtil o plástico preto foi superior ao marrom, mas não diferiu do solo descoberto. A produção diminuiu com a redução da lâmina de irrigação. O uso do agrotêxtil associado ao uso de cobertura do solo com plástico preto ou solo descoberto apresentou maior viabilidade econômica.
\end{abstract}

Palavras-chave: Cucumis melo L, filmes de polietileno, rendimento, irrigação.

\begin{abstract}
Melon yield and fruit quality as influenced by soil coverages, agrotextile and irrigation depth in dry season

Two experiments were carried out at the same time in Baraúna, Rio Grande do Norte State, Brazil, from October to December 2004, to evaluate different soil coverages and irrigation depth as well as the use of agrotextile on the melon yield. In the first experiment the agrotextile was used, but not in the second one. Both experiments were designed in a $5 \times 3$ factorial scheme in randomized complete blocks with two replications. The treatments of the factorial consisted of the combination of five soil coverages (films of yellow, brown, black and silvered polyethylene, and no soil coverages) with three irrigation depths $(100 \%, 84 \%$ and $67 \%$ of the standard water amount). The fruit number, mean fruit mass, marketable fruit yield, refused and total fruit yield were evaluated. The treatments with film of yellow polyethylene increased the marketable fruit yield in the absence of agrotextile. The fruit yield decreased with decreasing irrigation depths. The treatments with black polyethylene film or with nude soil associated with agrotextile had the best economic results.
\end{abstract}

Keywords: Cucumis melo L., polyethylene films, yield, irrigation.

(Recebido para publicação em 8 de agosto de 2006; aceito em 6 de novembro de 2007)

$\mathrm{O}$ melões nobres, especialmente o tipo Cantaloupe, têm sido bastante apreciados pelo mercado consumidor internacional, por serem mais saborosos e de alto valor nutritivo. Apesar de sua baixa conservação pós-colheita e de exigir maiores cuidados com relação ao manejo cultural pré e pós-colheita, são os mais produzidos no mundo (Alves et al., 2000), apresentando nos últimos anos expressiva expansão na região produtora dos pólos agrícolas Açu-Mossoró (RN) e Vale do Jaguaribe (CE) (Saldanha, 2004).

Em 1951, começou-se a utilizar no Japão o filme de PVC na agricultura e hoje é o país que mais utiliza essa técnica, mantendo oferta constante de produtos agrícolas, apesar de suas limitações de áreas agricultáveis e de seu clima adverso (Sganzerla, 1991). No Brasil, esta técnica só ganhou repercussão no início dos anos 70 com a utilização de filme de polietileno na cultura do morango em São Paulo (Goto, 1997). Na região Nordeste, especialmente no Pólo Agrícola Açu-Mossoró, na cultura do melão, a cobertura do solo com filme de polietileno é recente, sendo principalmente utilizada por médias e grandes empresas exportadoras.

Vários autores descrevem as inúmeras vantagens da cobertura do solo com plástico: melhor conservação da umidade; manutenção de temperatura mais constante; conservação da estrutura do solo, evitando a compactação e erosão; menor perda de adubos e corretivos por lixiviação, permitindo melhor aproveitamento destes pelo sistema radicular; proteção do sistema radicular contra danos de equipamentos; dispensa nas capinas ou redução da aplicação de herbicidas; influência direta sobre as pragas e doenças; proteção dos frutos do contato direto com o solo; aumento da precocidade das colheitas. $\mathrm{O}$ teor de umidade constante e a temperatura mais elevada dos solos com cobertura plástica favorecem a atividade microbiana e maior mineralização do nitrogênio orgânico, aumentando a disponibilidade deste nutriente para as plantas nas camadas mais superficiais do solo (Sampaio et al., 1999). Coberturas que apresentem maior refletância à luz solar tendem a apresentar maior efeito repelente a pulgões, tripes e mosca branca (Zapata et al., 1989).

$\mathrm{Na}$ região produtora de melão no $\mathrm{CE}$ e RN, começou-se a utilizar o agrotéxtil em 2001, associado à cobertura do solo com plástico (manta de tecido não tecido (TNT), visando inicialmente ao controle da mosca branca, provável transmissor do agente causador do amarelão 
do melão. Entretanto, nestes dois últimos anos, a manta tem sido adotada na região com a finalidade de controlar principalmente a mosca minadora, que se tornou a principal praga da cultura. O agrotêxtil é empregado no período que vai do plantio até o início de floração do melão. Mesmo com a popularização do agrotéxtil na região, nenhum trabalho científico foi realizado até agora com a finalidade de avaliar o efeito direto do agrotêxtil na produção dessa cultura.

$\mathrm{O}$ agrotêxtil é confeccionado a partir de longos filamentos de polipropileno, colocados em camadas e soldadas entre si, constituindo-se um material muito leve e de resistência suficiente para sua utilização na agricultura (Gregoire, 1989). O agrotêxtil pode ser colocado diretamente sobre a cultura após o transplantio, sobre o solo semeado ou com a utilização de uma estrutura de apoio (túneis).

O teor de água no solo está entre os principais fatores que afetam a produtividade das hortaliças, devido ao fato da água ser requerida como parte integrante dos vegetais e, sobretudo, por seu papel no transporte de nutrientes dentre outras funções vitais para o desenvolvimento das plantas (Medeiros et al., 2000). A necessidade de água das culturas se expressa normalmente pela taxa de evapotranspiração, que depende das condições climáticas, da disponibilidade hídrica no solo e da cobertura do terreno (Allen et al., 1998).

A estimativa da necessidade hídrica das culturas deve ser precisa o suficiente para suprir a quantidade de água requerida pela planta naquele determinado estádio de desenvolvimento. Caso contrário haverá déficit hídrico na planta que, de acordo com Herrera (2000), afeta os processos morfológicos e fisiológicos dos vegetais e a integração de todos esses efeitos conduz, geralmente, ao menor tamanho da planta, da área foliar e do rendimento na produção da cultivar, além de aumentar a suscetibilidade das plantas ao ataque de patógenos e alterar-lhes os reguladores de crescimento e hormônios.

A necessidade de água não é constante nos diversos tipos de melão. $\mathrm{O}$ Cantaloupe requer cerca de $25 \%$ a menos do que o amarelo, além de tolerar menores teores de água no solo (Allen et al., 1998). Água em excesso para esse tipo de melão produz frutos com tamanho acima do calibre desejado e reduz os sólidos solúveis totais (Almeida Neto, 2004). O uso de cobertura do solo com filme plástico elimina a evaporação direta da superfície do solo e, a cobertura da cultura com o agrotêxtil pode reduzir a transpiração da planta por aumentar a resistência ao fluxo de vapor da planta para a atmosfera, o que ao final poderá implicar na redução da evapotranspiração da cultura.

Considerando a importância da cultura do melão para a Região Nordeste, este trabalho teve como objetivo estudar o uso de cobertura do solo com filmes plásticos de diferentes cores, o uso do agrotêxtil e diferentes lâminas de irrigação na produção de melão Cantaloupe cultivado no período seco.

\section{MATERIAL E MÉTODOS}

O trabalho foi desenvolvido no município de Baraúna (RN), de outubro a dezembro de 2003. O solo da área é um Cambissolo Háplico, textura argilosa (EMBRAPA, 1999).

Foram realizados dois experimentos em uma mesma área, utilizando agrotêxtil em um e em outro não. $\mathrm{O}$ delineamento utilizado em cada ensaio foi de blocos casualizados completos, em esquema fatorial 5 x 3 com duas repetições. Os tratamentos resultaram das combinações de cinco tipos de cobertura: solo descoberto (testemunha) e cobertura do solo com plástico preto, prateado, amarelo e marrom e três lâminas de irrigação: 270 mm (100\% da lâmina padrão), 226 mm (84\% da lâmina padrão) e 182 mm (67\% da lâmina padrão). Subtende-se como lâmina padrão a quantidade de água estimada para o cultivo de melão sem cobertura do solo usando a metodologia da FAO (Allen et al., 1998).

Cada parcela experimental foi constituída de três fileiras de 6,0 m espaçadas de 2,0 m. A área útil por parcela foi de $30 \mathrm{~m}^{2}$, correspondendo a 20 plantas de cada uma das três fileiras de cada parcela.

O solo foi preparado com uma aração e duas gradagens, seguidas das confecções dos canteiros de $1,0 \mathrm{~m}$ de largura, distanciados entre eixos de 2,0 m. A adubação de fundação constou de 315 kg.ha- de MAP (fosfato monoamônico).

Irrigou-se por gotejamento, constituído de um conjunto moto-bomba, com estação de controle composto de filtro de disco, sistema de controle de vazão e pressão e um injetor de fertilizante tipo Venturi, tubulação principal em PVC rígido de $50 \mathrm{~mm}$, linhas laterais de polietileno flexível de $16 \mathrm{~mm}$ e gotejadores com vazão de $2,2 \mathrm{~L} \mathrm{~h}^{-1}$, para uma pressão de serviço de $100 \mathrm{kPa}$ e espaçados na linha de 0,50 m. Após a instalação do sistema de irrigação, foram colocados os plásticos nas parcelas dos tratamentos com cobertura, seguido da abertura dos orifícios de plantio, dois em cada gotejador distanciados $0,15 \mathrm{~m}$, com um vazador de $6 \mathrm{~cm}$ de diâmetro.

Utilizou-se o híbrido de melão 'Torreon', tipo Cantaloupe. O transplantio das mudas foi realizado 10 dias após a semeadura. $\mathrm{O}$ espaçamento adotado foi de duas plantas próximas de cada gotejador, resultando numa população de 20.000 plantas por hectare. As mudas foram produzidas em bandejas de poliestireno expandido de 128 células, utilizando o substrato comercial Golden Mix ${ }^{\circledR}$ (à base de fibra de coco). O estande foi corrigido através do replantio das mudas, quatro dias após o transplantio. $\mathrm{O}$ agrotêxtil foi colocado, no mesmo dia do transplantio das mudas, e retirado 28 dias após.

A água para irrigação foi proveniente de um poço do aqüífero calcário Jandaíra, com profundidade de $80 \mathrm{~m}$, que apresentou as características: $\mathrm{CE}=$ $1,7 \mathrm{dS} \mathrm{m} \mathrm{m}^{-1} ; \mathrm{pH}=6,9$; concentração de $\mathrm{Ca}=9,0 ; \mathrm{Mg}=3,0 ; \mathrm{Na}=5,0 ; \mathrm{K}=0,1 ;$ $\mathrm{HCO}_{3}=8,0$ e $\mathrm{Cl}=6,0 \mathrm{mmol}_{\mathrm{c}} \mathrm{L}^{-1}$.

A lâmina total de irrigação para o tratamento padrão foi calculada pela equação: $L T I=E T o \cdot K c \cdot T r \cdot U e^{-1}$, sendo LTI= lâmina total de irrigação $\left(\mathrm{mm} \mathrm{dia}{ }^{-1}\right) ; \mathrm{ETo}=$ evapotranspiração de referência $\left(\mathrm{mm} \mathrm{dia}^{-1}\right)$ estimada segundo o método Penman-Monteith, proposto pela FAO (Allen et al., 1998); Kc= coeficiente de cultura (calculado diariamente para irrigação localizada usando 
Tabela 1. Valores médios para o número de frutos mercado externo (NFE), número de frutos mercado interno (NFI), número de frutos comercializável (NFC), número de frutos totais (NTF), massa média de frutos mercado interno (MMFI), massa média de frutos comercializáveis (MMFC). (Mean values of fruits number for external and internal market, number of commercial fruits, number of total, mean mass of internal market, mean mass of commercial fruits). Mossoró, UFERSA, 2003.

\begin{tabular}{|c|c|c|c|c|c|c|}
\hline Fator/nível & $\begin{array}{c}\text { NFE } \\
\left(\text { frutos ha-1) }^{-1}\right)\end{array}$ & $\begin{array}{c}\text { NFI } \\
\text { (frutos ha-1) }\end{array}$ & $\begin{array}{c}\text { NFC } \\
\text { (frutos ha-1) }\end{array}$ & $\begin{array}{c}\text { NFT } \\
\text { (frutos ha-1) }\end{array}$ & $\begin{array}{l}\text { MMFI } \\
(\mathrm{g})\end{array}$ & $\begin{array}{c}\text { MMFC } \\
\text { (g) }\end{array}$ \\
\hline Sem agrotêxtil & $14666 b^{*}$ & 2645 a & $17311 \mathrm{~b}$ & 30442 b & $1421 a^{*}$ & 1061 a \\
\hline Com agrotêxtil & 17740 a & $1816 \mathrm{~b}$ & 19556 a & 35444 a & 1447 a & $1030 \mathrm{a}$ \\
\hline \multicolumn{7}{|c|}{ Lâminas de irrigação (mm) } \\
\hline $270(100 \%)$ & 15972 a & 3421 a & 19393 a & 34597 a & 1469 a & 1089 a \\
\hline $226(84 \%)$ & 16227 a & $1922 b$ & 18333 a & $32751 a b$ & 1485 a & $1044 a b$ \\
\hline $182(67 \%)$ & 16411 a & $1348 \mathrm{~b}$ & 17575 a & $31481 \mathrm{~b}$ & 1347 a & $1003 \mathrm{~b}$ \\
\hline \multicolumn{7}{|c|}{ Coberturas do solo } \\
\hline Solo descoberto & 17034 a & 1446 b & 18480 a & 29717 b & 1398 a & $993 \mathrm{~b}$ \\
\hline Plástico preto & $16120 \mathrm{a}$ & $2426 a b$ & 18546 a & 33990 a & 1509 a & 1091 a \\
\hline Plástico prateado & 16603 a & $2202 a b$ & 18805 a & 34714 a & 1313 a & $1036 a b$ \\
\hline Plástico amarelo & 16705 a & 2935 a & 19640 a & $33623 a b$ & 1466 a & $1058 a b$ \\
\hline Plástico marrom & 14554 a & $2142 a b$ & 16696 a & $32671 a b$ & 1484 a & $1050 \mathrm{ab}$ \\
\hline
\end{tabular}

*Médias seguidas de mesma letra, entre níveis de cada fator, não diferem entre si $(\mathrm{p}>0,05)$ pelo teste de Tukey (means followed by the same letter did not differ from each other; Tukey, $5 \%$ ).

planilha eletrônica elaborada conforme metodologia da FAO (Allen et al., 1998)). Utilizou-se para os estádios fenológicos da cultura I, III e final do ciclo os Kc basais de 0,15; 0,80 e 0,55. $\mathrm{Tr}=$ taxa de percolação profunda não controlável, estimada segundo Keller \& Blisner (1990), adotando-se o valor de 1,05. UE= uniformidade de vazão dos emissores, cujo valor medido foi de 0,96. O termo $\operatorname{Tr} \mathrm{UE}^{-1}$ representa o inverso da eficiência de aplicação de água.

As lâminas de irrigação préestabelecidas para o tratamento padrão, foram ajustadas ao longo do ciclo da cultura, através do monitoramento da umidade do solo. Para isso, foram instaladas baterias de três tensiômetros às profundidades de $15 ; 30$ e $45 \mathrm{~cm}$ em todas as parcelas do Bloco I do experimento sem agrotêxtil, onde foram feitas duas leituras diárias. Os valores préestabelecidos de lâminas de irrigação foram de $60 \%$ a $80 \%$ para L3 e L2, sendo que durante o ciclo ocorreram variações nesses índices de redução de acordo com a tolerância ao estresse hídrico em cada fase (Doorenbos \& Kassam, 1994). As lâminas de irrigação aplicadas nos períodos de 1 a 21, 22 a 35, 36 a 49 e 50 a 59 dias após o transplantio (DAT) para L1 foram de 51, 68, 99 e 52 $\mathrm{mm}$, respectivamente, tendo a cultura recebido para L2 e L3, 87 e 70\%, 80 e $60 \%, 85$ e $70 \%$ e 82 e $65 \%$ de L1 nos respectivos períodos, cujas evapotranspiração de referência correspondeu a 150, 91, 105 e 69 mm.

Foram realizadas fertirrigações diárias, seguindo as recomendações de adubação para cada estádio de desenvolvimento da cultura. As quantidades de nutrientes aplicados corresponderam a $11,72 \mathrm{~kg}$ de $\mathrm{MgO}, 11,53 \mathrm{~kg}$ de $\mathrm{CaO}$, $296,33 \mathrm{~kg}$ de $\mathrm{K}_{2} \mathrm{O}, 164,64 \mathrm{~kg}$ de $\mathrm{P}_{2} \mathrm{O}_{5}$ e $142,09 \mathrm{~kg}$ de $\mathrm{N}$, respectivamente, na forma de sulfato de magnésio; de nitrato de cálcio; de cloreto de potássio; de ácido fosfórico; de MAP; de ácido nítrico e de uréia.

As adubações em fundação e em cobertura (fertirrigações) foram efetuadas de acordo com a análise de solo e a quantidade de nutrientes exportados pela cultura (Crisóstomo et al., 2003) e ajustada para as doses semanalmente utilizadas pelos produtores da região.

O controle fitossanitário foi realizado através de pulverizações de acordo com as recomendações técnicas adotadas pela Fazenda $\mathrm{PH}$ visando ao controle, principalmente, de pragas como mosca branca, mosca minadora e doenças como Macrophomina e Rhizoctoniose. O controle de ervas da- ninhas nas parcelas sem cobertura foi feito através de duas capinas manuais com enxada e, para as parcelas com mulch, as ervas daninhas que surgiram próximas às covas foram eliminadas manualmente.

Durante a condução do experimento foram efetuadas duas viragens dos frutos, aos 37 e 46 dias após o transplantio, e também uma aplicação de diatomita sobre os frutos para evitar queimadura dos mesmos pelos raios solares. Foram realizadas cinco colheitas, entre 01/12/03 (57 dias após o transplantio) e 06/12/03. O ponto de colheita adotado foi a mudança de coloração da casca de verde escuro para verde claro e o início da rachadura da base do pedúnculo.

Foram avaliadas as características: número, massa média e produtividade de frutos comercializáveis (tipo exportação e mercado interno), refugos e totais. Considerou-se na classificação dos frutos os padrões de qualidade da Empresa em tipo, de acordo com o número de frutos por caixa (5 a 8), com capacidade de $6 \mathrm{~kg}$. Aqueles que não se enquadraram na classificação padronizada pela Empresa para encaixamento foram considerados refugos. Consideraram-se como refugos os frutos com danos mecânicos, queimados pelo sol, mancha de encosto e deformados. O tipo mercado interno foi considerado aquele constituído por frutos maiores que tipo 5 ou aqueles que apresentavam pequenos defeitos dentre os tipos 5 a 8 . Partes dos melões considerados refugos são comercializados a granel no mercado regional.

Foram realizadas análises conjuntas dos dois experimentos através do Software SAEG versão 8.0 (Ribeiro Junior, 2001) da UFV e a comparação entre as médias das características avaliadas foi feita pelo teste de Tukey a 5\% de probabilidade (Gomes, 1987).

\section{RESULTADOS E DISCUSSÃO}

Para número de frutos mercado externo (NFE), número de frutos comercializáveis (NFC) e número de frutos totais (NFT), o uso do agrotêxtil proporcionou aumentos significativos de $20,96 \%, 12,96 \%$ e $16,43 \%$, respecti- 
vamente, e redução para números de frutos mercado interno (NFI) de 31,30\% (Tabela 1). Plantas das parcelas que receberam o tratamento agrotêxtil desenvolveram-se até os 28 dias após o transplantio, sem a infestação de pragas, principalmente da mosca minadora, o que contribuiu para a boa qualidade de massa foliar e conseqüentemente maior eficiência fotossintética, resultando em maior número de frutos. Menor número de frutos para o mercado interno foi verificado no uso do agrotêxtil, muito provavelmente porque este tratamento permitiu maior pegamento de frutos por planta, promovendo maior quantidade de frutos tipo exportação e menor quantidade de frutos tipo mercado interno.

A redução da lâmina de irrigação determinou uma diminuição no NFI, sendo de $43,82 \%$ e de $60,60 \%$, respectivamente para L2 e L3 (Tabela 1). Saldanha et al. (2003), constataram que a redução das lâminas de irrigação também determinava diminuição no número de frutos para mercado interno. Isso sugere que a redução da lâmina implica em déficit hídrico importante para NFI. O estádio de frutificação, que vai do pegamento dos frutos até o início da maturação, é o mais crítico do meloeiro quanto à deficiência de água no solo, reduzindo o pegamento e o tamanho de frutos, comprometendo a produção. Para NFT, as reduções de lâminas de irrigação de $16 \%$ e $33 \%$ implicaram em queda de NFT de 5,34\% e 9,0\%, respectivamente (Tabela 1). Esses resultados concordam com os de Almeida Neto et al. (2003) e Andrade et al. (2004), onde o aumento das lâminas proporcionou incremento no número de frutos comercializáveis e totais. Bezerra \& Mourão (2000) observaram que o melhor desempenho da cultura foi obtido no tratamento que forneceu a maior lâmina de irrigação. O melhor desempenho da cultura com a aplicação da lâmina padrão, possivelmente, possibilitou adequado suprimento de água no solo e permitiu melhor disponibilidade desse recurso e de nutrientes para a cultura (Bezerra \& Mourão, 2000).

O uso da cobertura plástica do solo aumentou o NFI, quando se usou o plástico amarelo (102,97\%), NFR, quando se utilizaram os plásticos pretos $(37,44 \%)$,

Tabela 2. Valores médios para a massa média, em gramas, de frutos mercado externo (MMFE) e de frutos totais (MMFT). (Mean values in grams of mean mass of fruits for external market and for total fruits). Mossoró, UFERSA, 2003.

\begin{tabular}{|c|c|c|c|c|c|c|}
\hline \multirow{2}{*}{$\begin{array}{l}\text { Lâminas de } \\
\text { irrigação } \\
(\mathrm{mm})\end{array}$} & \multirow[b]{2}{*}{ Agrotêxtil } & \multicolumn{5}{|c|}{ Coberturas do solo } \\
\hline & & $\begin{array}{c}\text { Solo } \\
\text { descoberto }\end{array}$ & $\begin{array}{c}\text { Polietileno } \\
\text { preto }\end{array}$ & $\begin{array}{c}\text { Polietileno } \\
\text { prateado }\end{array}$ & $\begin{array}{c}\text { Polietileno } \\
\text { amarelo }\end{array}$ & $\begin{array}{c}\text { Polietileno } \\
\text { marrom }\end{array}$ \\
\hline \multicolumn{7}{|c|}{ Frutos mercado externo (MMFE). } \\
\hline \multirow{2}{*}{$270(100 \%)$} & Sem agrotêxtil & $1009 A^{*} a^{+}$ & $1063 \mathrm{Aa}$ & $1027 \mathrm{Aa}$ & $1006 \mathrm{Aa}$ & $1047 \mathrm{Aa}$ \\
\hline & Com agrotêxtil & $959 \mathrm{Aa}$ & $1011 \mathrm{Aa}$ & $1003 \mathrm{Aa}$ & $1030 \mathrm{Aa}$ & $948 \mathrm{Aa}$ \\
\hline \multirow{2}{*}{$226(84 \%)$} & Sem agrotêxtil & $1027 \mathrm{Aa}$ & $947 \mathrm{Ab}$ & $948 \mathrm{Aa}$ & $1040 \mathrm{Aa}$ & $1044 \mathrm{Aa}$ \\
\hline & Com ag rotêxtil & $917 \mathrm{Ba}$ & $1103 \mathrm{Aa}$ & $1001 \mathrm{ABa}$ & $942 \mathrm{ABa}$ & $943 \mathrm{ABa}$ \\
\hline \multirow{2}{*}{$182(67 \%)$} & Sem agrotêxtil & $877 \mathrm{Aa}$ & $1009 \mathrm{Aa}$ & $975 \mathrm{Aa}$ & $1025 \mathrm{Aa}$ & $949 \mathrm{Aa}$ \\
\hline & Com agrotêxtil & $955 \mathrm{Aa}$ & $1028 \mathrm{Aa}$ & $988 \mathrm{Aa}$ & $877 \mathrm{Ab}$ & $1010 \mathrm{Aa}$ \\
\hline \multicolumn{7}{|c|}{ Frutos totais (MMFT) } \\
\hline & Sem agrotêxtil & $843 A^{*} a+$ & $834 \mathrm{Aa}$ & $820 \mathrm{Aa}$ & $892 \mathrm{Aa}$ & $842 \mathrm{Aa}$ \\
\hline & Com agrotêxtil & $824 \mathrm{Aa}$ & $866 \mathrm{Aa}$ & $830 \mathrm{Aa}$ & $816 \mathrm{Ab}$ & $792 \mathrm{Aa}$ \\
\hline $270(100 \%)$ & & $820 \mathrm{Aa}$ & $862 \mathrm{Aa}$ & $870 \mathrm{Aa}$ & $896 \mathrm{Aa}$ & $898 \mathrm{Aa}$ \\
\hline $226(84 \%)$ & & $858 \mathrm{Aa}$ & $846 \mathrm{Aa}$ & $821 \mathrm{Aab}$ & $838 \mathrm{Aa}$ & $811 \mathrm{Ab}$ \\
\hline $182(67 \%)$ & & $822 \mathrm{Aa}$ & $843 \mathrm{Aa}$ & $783 \mathrm{Ab}$ & $828 \mathrm{Aa}$ & $742 \mathrm{Ab}$ \\
\hline
\end{tabular}

Letras iguais, maiúsculas* nas linhas e minúsculas ${ }^{+}$nas colunas, para cada lâmina de irrigação, não diferem entre si ao nível de $5 \%$ de probabilidade pelo teste de Tukey para massa média de frutos mercado externo. Para frutos totais, letras minúsculas comparam presença ou não do agrotêxtil e entre lâminas dentro de cada tipo de cobertura (The same capital* letter in the lines and small letters in the column, for each irrigation depth, did not differ from each other; Tukey, 5\%, for average mass of external market fruits. For total fruits yield, small letters compare the presence or not of non-woven and, among irrigation depth, in each coverage type).

prateado $(41,58 \%)$ e marrom $(42,16 \%)$, e o NFT, quando se utilizaram os plásticos preto $(14,38 \%)$ e prateado $(16,82)$, não ocorrendo aumento significativo para NFE e NFC (Tabela 1).

O maior valor de NFI para o plástico amarelo está associado à grande quantidade de frutos de maior calibre produzidos. Câmara (2004), trabalhando com o melão amarelo no período chuvoso, verificou que as coberturas do solo com os plásticos prateado e marrom registraram valores superiores ao solo descoberto.

O efeito do tipo de cobertura do solo na massa média de frutos exportação (MMFE) nas diversas combinações de uso do agrotêxtil ou não, com lâminas de irrigação, resultou em diferença significativa entre as médias (Tabela 2) apenas quando se utilizou o agrotêxtil e aplicou-se a lâmina de irrigação L2, onde a cobertura de solo com plástico preto foi superior ao solo descoberto.

Analisando o efeito do agrotêxtil dentro de cada lâmina de irrigação e tipos de cobertura do solo, verificou-se efeito positivo de seu uso na MMFE apenas para L2 e plástico preto. Para L3 e plástico amarelo houve redução da MMFE (Tabela 3). Provavelmente, o uso do agrotêxtil associado ao plástico preto diminuiu a temperatura na superfície do solo no período inicial, contribuindo para se obter frutos tipo exportação, de maior calibre. Por outro lado, para o plástico amarelo, que proporciona maior reflexão de radiação solar, o uso do agrotêxtil não contribuiu para a redução da evapotranspiração e conseqüente redução do estresse, pois o mesmo é transparente e provoca acúmulo de radiação solar de ondas longas, ocorrendo maior transpiração.

A massa média de frutos totais (MMFT) foi diminuída de 892 para 816 g devido ao uso do agrotêxtil para cobertura de solo com plástico amarelo, enquanto para as outras coberturas o agrotêxtil não afetou a massa média de frutos totais (Tabela 3). A MMFT não diferiu significativamente em tipos de coberturas na presença ou ausência de agrotêxtil.

O MMFT diferiu significativamente entre lâminas apenas para as coberturas de solo com plástico prateado e marrom, havendo diminuição da massa 
Tabela 3. Valores médios para a produtividade de frutos comercializáveis (PFC), em t ha-1. (Mean values for yield of commercial fruits, in $\mathrm{t} \mathrm{ha}^{-1}$ ). Mossoró, UFERSA, 2003.

\begin{tabular}{llllll}
\hline \multirow{2}{*}{ Agrotêxtil } & \multicolumn{5}{c}{ Coberturas de solo } \\
\cline { 2 - 6 } & $\begin{array}{c}\text { Solo } \\
\text { descoberto }\end{array}$ & $\begin{array}{c}\text { Plástico } \\
\text { preto }\end{array}$ & $\begin{array}{c}\text { Plástico } \\
\text { prateado }\end{array}$ & $\begin{array}{c}\text { Plástico } \\
\text { amarelo }\end{array}$ & $\begin{array}{c}\text { Plástico } \\
\text { marrom }\end{array}$ \\
\hline Sem agrotêxtil & $15,89 \mathrm{~B}^{*} \mathrm{~b}+$ & $18,74 \mathrm{ABa}$ & $18,24 \mathrm{ABa}$ & $20,68 \mathrm{Aa}$ & $18,30 \mathrm{Aba}$ \\
Com agrotêxtil & $20,69 \mathrm{ABa}$ & $21,45 \mathrm{Aa}$ & $20,67 \mathrm{ABa}$ & $20,60 \mathrm{ABa}$ & $16,83 \mathrm{Ba}$ \\
\hline
\end{tabular}

Letras iguais, maiúsculas* nas linhas e minúsculas ${ }^{+}$nas colunas, não diferem entre si ao nível de 5\% de probabilidade pelo teste de Tukey (means followed by the same capital letter* in the lines and small letters in the colums, did not differ from each other; Tukey, 5\%).

Tabela 4. Valores médios para a produtividade de frutos mercado externo (PFE), produtividade de frutos mercado interno (PFI), produtividade de frutos comercializáveis (PFC) e produtividade de frutos totais (PFT). (Mean values for yield of fruits for external and internal market, yield of commercial fruits, and yield of total fruits). Mossoró, UFERSA, 2003.

\begin{tabular}{lcccc}
\hline Fator/níveis & PFE (t ha-1) & PFI (t ha $\left.\mathbf{~}^{-1}\right)$ & PFC (t ha-1) & PFT (t ha-1) \\
\hline Sem agrotêxtil & $14,61 \mathrm{~b}^{*}$ & $3,76 \mathrm{a}$ & & $25,74 \mathrm{~b}$ \\
Com agrotêxtil & $17,31 \mathrm{a}$ & $2,73 \mathrm{~b}$ & & $29,28 \mathrm{a}$ \\
\hline Coberturas do solo & & & & \\
\hline Solo descoberto & $16,27 \mathrm{a}$ & $2,02 \mathrm{~b}$ & & $24,75 \mathrm{~b}$ \\
Plástico Preto & $16,45 \mathrm{a}$ & $3,64 \mathrm{ab}$ & & $28,90 \mathrm{a}$ \\
Plástico prateado & $16,39 \mathrm{a}$ & $3,06 \mathrm{ab}$ & & $28,66 \mathrm{a}$ \\
Plástico amarelo & $16,32 \mathrm{a}$ & $4,31 \mathrm{a}$ & & $28,58 \mathrm{a}$ \\
Plástico marrom & $14,36 \mathrm{a}$ & $3,20 \mathrm{ab}$ & & $26,67 \mathrm{ab}$ \\
\hline Lâminas de irrigação (mm) & & & \\
\hline 270 (100\%) & $16,07 \mathrm{a}^{*}$ & $4,98 \mathrm{a}$ & $21,06 \mathrm{a}$ & $30,05 \mathrm{a}$ \\
$226(84 \%)$ & $16,16 \mathrm{a}$ & $2,86 \mathrm{~b}$ & $19,02 \mathrm{~b}$ & $27,24 \mathrm{ab}$ \\
$182(67 \%)$ & $15,65 \mathrm{a}$ & $1,89 \mathrm{~b}$ & $17,54 \mathrm{~b}$ & $25,24 \mathrm{~b}$ \\
\hline
\end{tabular}

*Médias seguidas de mesma letra nas colunas entre níveis de cada fator, não diferem entre si $(\mathrm{p}>0,05)$ pelo teste de Tukey (*means followed by the same letter in the column among levels of each factor, did not differ from each other $(p>0,05))$.

média de frutos totais à medida que a lâmina de irrigação foi reduzida (Tabela 3). Esse resultado diverge do encontrado por Almeida Neto et al. (2003) em que a diminuição da lâmina de irrigação proporcionou maior massa média total independente dos tipos de coberturas de solo.

A massa média de frutos comercializáveis (MMFC) foi diminuída com a redução da lâmina de irrigação, passando de 1089 g para 1003 g quando a lâmina de irrigação variou de L1 para L3 (Tabela 1). Câmara et al. (2007) trabalhando com melão amarelo, observaram que a massa média de frutos comercializáveis, não diferiu em função das lâminas de irrigação aplicadas. A cobertura de solo com plástico preto, embora não diferindo dos outros plásticos, produziu frutos comercializáveis com peso significativamente superior ao produzido sem co- berto, e, com o agrotêxtil, a menor produtividade foi obtida com o plástico marrom. Isto sugere uma viabilidade de uso do agrotêxtil em solo descoberto ou associado ao plástico preto, prateado ou amarelo (Tabela 4). Andrade et al. (2004), trabalhando com melão Cantaloupe, Torreon, com as mesmas coberturas de solo, identificaram que, com exceção do plástico marrom, todos os outros plásticos proporcionaram valores superiores ao solo descoberto. Entretanto, Araújo et al. (2003) e Ferreira et al. (2005) também não verificaram efeito significativo das coberturas do solo com filmes plásticos preto, prateado e solo descoberto sobre a produtividade de frutos comercializáveis de melão amarelo.

$\mathrm{O}$ uso do agrotêxtil proporcionou aumento na produtividade de frutos mercado externo, frutos refugos e totais, e redução na produtividade de frutos mercado interno (Tabela 4). A presença do agrotêxtil aumentou o vingamento de flores, contribuindo para frutos menores. Os frutos para o mercado externo são aqueles de menor calibre.

A maior produtividade para o mercado interno foi obtida utilizando-se o plástico amarelo, e as menores produtividades de frutos totais ocorreram na utilização do solo descoberto e plástico marrom (Tabela 4). Saldanha et al. (2003) verificaram que o plástico amarelo apresentou valor médio para produtividade de frutos tipo nacional superior à média dos demais tipos de cobertura; conseqüentemente, observou-se valor médio menor na produtividade de frutos tipo exportação quando comparado com a média dos demais filmes plásticos.

É provável que o plástico amarelo, por proporcionar maior capacidade reflectiva em relação às demais coberturas, transmitiu menos energia ao solo, reduzindo-lhe a temperatura na camada superficial e reduzindo a ETo, aumentando a água disponível para as plantas; interferindo, assim, de modo positivo no crescimento e desenvolvimento do meloeiro, resultando em média, em maior número de frutos para o mercado interno (frutos maiores).

A redução da lâmina de irrigação implicou em menor produtividade de 
frutos mercado interno, comercializáveis e frutos totais (Tabela 4). Esses resultados se aproximam dos encontrados por Aragão Júnior et al. (1991), que estudaram o comportamento de quatro cultivares de melão Cantaloupe, 'Torreon' cultivado no verão, submetidos aos níveis de umidade de $95 ; 75$ e 55\% da água disponível no solo, e verificaram que a irrigação baseada no nível de $95 \%$ resultou em maior produtividade de frutos comercializáveis. Saldanha et al. (2003), Almeida Neto, et al. (2003) e Andrade et al. (2004), trabalhando com melão Cantaloupe, observaram também incremento na produtividade de frutos comercializáveis com o aumento das lâminas de irrigação.

O uso do agrotêxtil aumenta o número de frutos e a produtividade do melão. Na ausência do agrotêxtil, a cobertura do solo usando plástico amarelo aumenta a produtividade comercial, enquanto que, na presença do agrotêxtil, o solo descoberto equipara-se ao solo com cobertura. A produção de melão diminui com a redução da lâmina de irrigação.

\section{AGRADECIMENTOS}

Os autores agradecem ao CNPq pelo financiamento desta pesquisa e à Fazenda PH, localizada no município de Baraúna, pelo apoio na instalação e condução do experimento.

\section{REFERÊNCIAS}

ALLEN RG; PEREIRA LS; RAES D; SMITH M. 1998. Crop evapotranspiration: guidelines for computing crop water requirements. Rome: FAO. 279 p. (FAO, Irrigation and Drainage Paper, 56).

ALVES RE; PIMENTEL CR; MAIA CE; CASTRO EB; VIANA FM; COSTA FV; ANDRADE GG; FILGUEIRAS HAC; ALMEIDA JHS; MENEZES JB; COSTA JG; PEREIRA LSE. 2000. Manual de melão para exportação. Brasília: Embrapa, 51p.
ALMEIDA NETO AJ. 2004. Produção e qualidade de melão Cantaloupe influenciada por coberturas do solo e lâminas de irrigação em solo argiloso. 74p. (Tese mestrado). Escola Superior de Agricultura de Mossoró (ESAM), Mossoró-RN.

ALMEIDA NETO AJ; MEDEIROS JF; NEGREIROS MZ; BEZERRA NETO F; LEITÃO MMVB; ESPÍNOLA SOBRINHO J; PÔRTO DRQ; COSTA WPL. 2003. Produção de melão Cantaloupe influenciada sob diferentes tipos de cobertura e lâminas de irrigação em solo de textura média. Horticultura Brasileira 21, Suplemento 2. (CD-ROM)

ANDRADE PCSG; NEGREIROS MZ; MEDEIROS JF; LIMA JÚNIOR OJ; SANTOS SCL; BEZERRA NETO F; LISBOA RCC. 2004. Produção de melão Cantaloupe cultivado com diferentes coberturas do solo e lâminas de irrigação. Horticultura Brasileira 22, Suplemento. (CD ROM).

ARAGÃO JÚNIOR TC; MAGALHÃES CA; SANTOS CSV. 1991. Efeitos de níveis de umidade no solo em cultivares de melão (Cucumis melo L).. Fortaleza: EPACE, 16 p. Boletim de Pesquisa, 16.

ARAÚJO AP; NEGREIROS MZ; BEZERRA NETO FB; PEDROSA JF; FERREIRA RLF. 2003. Rendimento de melão amarelo cultivado em diferentes tipos de coberturas do solo e métodos de plantio. Horticultura Brasileira 21: 123-126.

BEZERRA FML; MOURÃO RMB. 2000. Produtividade e qualidade de frutos de melão em função de diferentes níveis de irrigação. Horticultura Brasileira 18: 601-603. Suplemento (Resumo expandido).

CÂMARA MJT. 2004. Produção e qualidade de melão amarelo influenciado por coberturas do solo e lâminas de irrigação no período chuvoso. 80p. (Tese mestrado). Escola Superior de Agricultura de Mossoró (ESAM), Mossoró-RN.

CÂMARA MJT; NEGREIROS MZ; MEDEIROS JF; BEZERRA NETO F; BARROS JÚNIOR AP. 2007. Produção e qualidade de melão amarelo influenciado por coberturas do solo e lâminas de irrigação no período chuvoso. $\mathrm{Ci}$ ência Rural 37: 58-63.

COSTA FA; MEDEIROS JF; NEGREIROS MZ; BEZERRA NETO F; PÔRTO DRQ; CHAVES SWP; DANTAS KN. 2002. Rendimento de melão cantaloupe em diferentes coberturas de solo e lâminas de irrigação. Caatinga 15: 4955.

CRISÓSTOMO JR; CARDOSO JW; SANTOS AA; CARDOSO JE; BLEICHER E; ROSSETTI AG; LIMA RN; FREITAS JG. 2003. Desempenho de híbridos de melão amarelo no Ceará e no Rio Grande do Norte, no período de 1999-2001. Embrapa: Fortaleza. (Comunicado Técnico).
DOORENBOS J; KASSAM AH. 1994. Efeito da água no rendimento das culturas. Trad. de GHEYI HR; SOUSA AA; DAMASCENO FAV; MEDEIROS JF. Campina Grande: UFPB, 306 p. (FAO. Estudos de Irrigação e Drenagem, 33)

EMBRAPA. 1999. Centro Nacional de Pesquisa do Solo. Sistema brasileiro de classificação de solos - Brasília: Embrapa Produção de Informação; Rio de Janeiro: Embrapa Solos, 412p.

FERREIRA RLF; NEGREIROS MZ; LEITÃO MMVB; PEDROSA JF; NOGUEIRA ICC; ESPÍNOLA SOBRINHO J; ARAÚJO AP. 2005. Rendimento e qualidade de melão em diferentes coberturas de solo e métodos de plantio. Revista Ceres 52: 325-334.

GOMES PF. 1987. Curso de estatística experimental. São Paulo: Nobel, 435p.

GOTO R. 1997. Plasticultura nos trópicos: uma avaliação técnico-econômica. Horticultura Brasileira 15: 163-65, Suplemento.

GREGOIRE P. 1989. Los no tejidos y la protección de los productos hortícolas. Hortic. 44: 61-64.

HERRERA JB. 2000. Necesidades de agua y programación de riegos. Madrid: MAPA, CENTER. (Apostila).

KELLER J; BLIESNER RD. 1990. Sprinkler and trickler irrigation. New York: Van Nostrand Reinhold, 652p.

MEDEIROS JF; NASCIMENTO IB; COSTA MC; SCALOPPI EJ. 2000. Produção de melão sob diferentes lâminas de água com dois níveis de salinidade. Horticultura Brasileira 18: 612-614, Suplemento.

RIBEIRO JÚNIOR JI. 2001. Análise estatística no SAEG. Viçosa: UFV, 301p.

SALDANHA TRFC. 2004. Produção e qualidade de melão Cantaloupe cultivado sob condições diferentes tipos de cobertura do solo e lâminas de irrigação. 2004. 82p. (Tese mestrado). Escola Superior de Agricultura de Mossoró (ESAM), Mossoró-RN.

SALDANHA TRFC; MEDEIROS JF; NEGREIROS MZ; BEZERRA NETO F; ALMEIDA NETO AJ; OLIVEIRA EQ. 2003. Rendimento do melão 'Torreon' cultivado em solo arenoso sob diferentes tipos de cobertura e lâminas de irrigação. Horticultura Brasileira 21, Suplemento. (CD-ROM).

SAMPAIO RA; FONTES PCR; SEDIYAMA CS. 1999. Resposta do tomateiro a fertirrigação potássica e cobertura plástica do solo. Pesquisa Agropecuária Brasileira 34: 21-30.

SGANZERLA E. 1991. Nova Agricultura: A fascinante arte de cultivar com os plásticos. 4 ed., Porto Alegre: Plasticultura Gaúcha, 303p.

ZAPATA M; CABRERA P; BAÑON S; ROTH P. 1989. El melon. Madrid, Mundi-Prensa, 174p. 